\title{
Descrição do padrão de venação foliar em Spathicarpa Hook. (Araceae) ${ }^{1}$
}

\author{
Luciano Coêlho Milhomens Fonsêca², Carolyn Elinore Barnes Proença ${ }^{2,4}$ e Eduardo Gomes Gonçalves ${ }^{3}$
}

Recebido em 16/03/2006. Aceito em 29/08/2006

\begin{abstract}
RESUMO - (Descrição do padrão de venação foliar em Spathicarpa Hook. (Araceae)). O estudo e a caracterização da venação foliar representam uma possibilidade de auxílio no reconhecimento de grupos taxonômicos identificados, predominantemente, com base em caracteres reprodutivos como o gênero Spathicarpa Hook. (Araceae). O presente estudo teve como objetivos: apresentar um método eficiente para diafanização de folhas similares às de Spathicarpa Hook.; descrever o padrão de venação das folhas de Spathicarpa gardneri Schott, Spathicarpa hastifolia Hook., Spathicarpa lanceolata Engl. e Spathicarpa sagittifolia Schott; e testar a utilização da arquitetura foliar de Spathicarpa Hook. como ferramenta taxonômica capaz de fornecer características diagnósticas vegetativas no gênero. Em linhas gerais, a técnica de diafanização consistiu inicialmente em submeter folhas frescas, estocadas em álcool etílico $70 \%$ com detergente comercial, ao hidróxido de sódio (5\%) e hipoclorito de sódio (5\%) para clareamento e alvejamento, respectivamente. Em seguida, estas passaram por uma bateria de desidratação etanólica crescente (10 a 100\%) e por uma série com xileno (xileno-etanol 100\% 1:1 e xileno). Foram então coradas com safranina e colocadas novamente em xileno-etanol 100\% 1:1 para diferenciar. Das quatro espécies estudadas, somente Spathicarpa lanceolata Engl. apresenta características vegetativas diagnósticas, não sendo possível diferenciar, com base na arquitetura foliar, as demais espécies.
\end{abstract}

Palavras-chave: Arquitetura foliar, Técnica de diafanização, lóbulos

\begin{abstract}
Description of leaf venation pattern in Spathicarpa Hook. (Araceae)). Characterization of leaf venation can help in the recognition of taxonomic groups that are identified primarily on the basis of reproductive characteristics such as genus Spathicarpa Hook. (Araceae). This study aims to provide an efficient technique for clearing leaves that are similar to those of Spathicarpa Hook., to describe the leaf venation pattern of Spathicarpa gardneri Schott, Spathicarpa hastifolia Hook., Spathicarpa lanceolata Engl. and Spathicarpa sagittifolia Schott, and to test the use of leaf architecture as a tool for taxonomic recognition of Spathicarpa Hook. species. In general, the leaf clearing technique initially involved placing leaves in $70 \%$ ethyl alcohol with commercial detergent, sodium hydroxide $(5 \%)$ and sodium hypochloride for clearing and whitening, respectively. The leaves were then run through an ethanol dehydration series (10 to $100 \%$ ) and through a xylene series (xylene-ethanol 100\% 1:1 and xylene). Lastly, leaves were died with safranin and again placed in xylene-ethanol 100\% 1:1 to differentiate. Of the four species, only Spathicarpa lanceolata Engl. presented diagnostic vegetative characteristics. It was not possible to distinguish amongst the other species based only on leaf architecture.
\end{abstract}

Key words: leaf architecture, leaf-clearing technique, lobules

\section{Introdução}

As folhas são, tipicamente, estruturas simétricas bilateralmente achatadas, oriundas das células laterais do meristema apical do caule (Harper \& Freeling 1996) em um padrão característico que varia com a espécie. Exibem variados graus de complexidade, distribuídos entre estruturas simples e altamente subdivididas (Sinha 1999) e podem diferir não somente entre indivíduos de uma mesma população, mas dentro da mesma planta (McCauley \& Evert 1988).

A morfologia das folhas sempre desempenhou papel importante na sistemática vegetal como um todo, particularmente para caracterizar e identificar taxa onde a variação nas estruturas florais não é informativa (Stace 1989). As características foliares também podem ser utilizadas em estudos evolutivos, sendo consideradas tão úteis quanto características florais, morfologia do pólen e a maioria das características anatômicas utilizadas tradicionalmente na sistemática (Hickey \& Taylor 1991).

A caracterização da arquitetura das folhas de dicotiledôneas e algumas monocotiledôneas, no que diz respeito à forma e outros elementos ligados à expressão da estrutura foliar, como a venação, tem se desenvolvido como resultado de uma pesquisa

\footnotetext{
1 Parte da Dissertação de Mestrado do primeiro Autor

2 Universidade de Brasília, Programa de Pós-Graduação em Botânica, Departamento de Botânica, C. Postal, 4457, 70919-970 Brasília, DF, Brasil(cproenca@unb.br)

3 Universidade Católica de Brasília, Curso de Ciências Biológias, Prédio São Gaspar Bertoni, sala M-206, QS-7, Lote 1 - EPTC, 72030-170 Taguatinga, DF Brasil (eduardog@ucb.br)

4 Autor para correspondência: cproenca@unb.br
} 
profunda visando a identificação de fósseis (Hickey 1973). A incorporação deste sistema na corrente sistemática representou grande avanço nas possibilidades de classificação e diferenciação de grupos problemáticos (Leaf Architecture 1999).

A compreensão da arquitetura das folhas, através da diafanização (técnica que consiste em tratar amostras biológicas de modo a torná-las semitransparentes, segundo Kraus \& Arduin 1997), pode fornecer importantes subsídios taxonômicos, correntemente utilizados por diversos autores. Dickison (1987) estudou a morfologia e a anatomia das Staphyleaceae. Hershkovitz (1992) utilizou a morfologia foliar para propor que Cistanthe tweedyi (A. Gray) Hershkovitz permaneça em Cistanthe Spach, rejeitando sua transferência para Lewisia Pursh (Portulacaceae). Dede (1962) estudou 80 gêneros de Rutaceae, apresentando sete tipos de venação básicos baseados na relação espacial existente entre o padrão de venação e as cavidades secretoras. Hickey \& Taylor (1991) forneceram uma concisa e acurada descrição da arquitetura foliar de Ticodendron Gómez-Laur. \& L.D. Gómez (Ticodendraceae), além de inferirem um padrão evolutivo e postularem relacionamentos filogenéticos com algumas famílias e gêneros próximos.

As folhas das Araceae são, comumente, descritas com base em particularidades da forma da folha, das bainhas e dos pecíolos mas outras abordagens foram utilizadas por outros autores. Ray $(1987 \mathrm{a} ; \mathrm{b} ; 1988)$ classifica os tipos foliares com base em seu relacionamento com a organização dos ramos, ou seja, os termos aplicados não descrevem aspectos da folha, mas características dos caules e de como estas folhas estão inseridas. Murata (1990), considerando a organização dos ramos (filotaxia, posição relativa das folhas e catafilos e padrões de elongamento) e peculiaridades na ramificação e na produção das folhagens e das inflorescências, além do número de cromossomos, propõe mudanças na classificação do gênero Typhonium Schott.

Além disso, as Araceae apresentam acentuado polimorfismo foliar. Ray (1987b) reconhece dois ciclos de produção de folhas morfologicamente distintas em Syngonium Schott. Ray (1990), estudando os padrões de desenvolvimento das folhas, apresenta aspectos de produção foliar relacionados com isomorfia, alomorfia e metamorfose, neste último ressaltando a ocorrência de abrupta mudança na forma foliar.

Assim, Araceae é uma família na qual são evidentes padrões elaborados de desenvolvimento dos ramos e produção das folhas, tendo estes reais implicações taxonômicas. Porém, são necessários mais estudos voltados para a morfologia foliar, sobretudo, sobre a arquitetura foliar que pode ocasionar avanços nas possibilidades de classificação e diferenciação de grupos problemáticos, notoriamente presentes em Araceae.

Ressalta-se ainda a dificuldade de identificação das espécies de Araceae somente com critérios vegetativos, pois as características diagnósticas são muitas vezes florais, sendo necessário, até mesmo, o cultivo até o florescimento para uma adequada determinação (Croat 1985).

A tribo Spathicarpeae representa um dos grupos mais pobremente compreendido dentro das Araceae. Dez gêneros têm sido reconhecidos na Tribo: Asterostigma Fisch. \& C.A. Mey., Croatiella E.G. Gonç., Gearum N.E.Br., Gorgonidium Schott, Incarum E.G. Gonç., Mangonia Schott, Spathantheum Schott, Spathicarpa Hook., Synandrospadix Engl. e Taccarum Brongn. ex Schott (Gonçalves et al., no prelo).

O gênero Spathicarpa é amplamente distribuído no Brasil extra-amazônico, ocorrendo do Ceará ao Rio Grande do Sul, além da Argentina, Paraguai, Uruguai e Bolívia, em altitudes de 0 a $1.100 \mathrm{~m}$. É composto, em sua maioria, por ervas geófitas, crescendo em solos bem drenados e por uma espécie helofítica (Spathicarpa lanceolata Engl.), que ocorre em banhados no sul do Brasil e Paraguai.

Gonçalves et al. (no prelo) utilizou dois marcadores moleculares (trnL-F e matK), uma matriz fenotípica e combinações destes para construir um cladograma da Tribo Spathicarpeae. O clado contendo o gênero Spathicarpa Hook. apresenta-se monofilético, com quatro espécies reconhecíveis: Spathicarpa gardneri Schott, Spathicarpa hastifolia Hook., Spathicarpa lanceolata Engl. e Spathicarpa sagittifolia Schott.

Porém, apesar de distintas do ponto de vista molecular, quanto à descrição morfológica destas quatro espécies, Gonçalves (dados não publicados), sobretudo considerando os aspectos vegetativos, apresentou algumas considerações importantes: Spathicarpa hastifolia Hook. é uma espécie de grande polimorfismo foliar, fato que causa dificuldades de circunscrição da espécie, principalmente com relação a Spathicarpa gardneri Schott e Spathicarpa sagittifolia Schott. Spathicarpa lanceolata Engl. parece ser uma espécie bem distinta 
dentro do gênero, tanto do ponto de vista morfológico, quanto ecológico.

O presente trabalho tem como objetivos: apresentar um método eficiente para diafanização de folhas similares às de Spathicarpa Hook.; descrever o padrão de venação das folhas de Spathicarpa gardneri Schott, Spathicarpa hastifolia Hook., Spathicarpa lanceolata Engl. e de Spathicarpa sagittifolia Schott; e testar a utilização da arquitetura foliar de Spathicarpa Hook. como ferramenta taxonômica capaz de fornecer características diagnósticas vegetativas entre estas quatro espécies.

\section{Material e métodos}

As folhas de Spathicarpa gardneri Schott, Spathicarpa hastifolia Hook., Spathicarpa lanceolata Engl. e Spathicarpa sagittifolia Schott foram coletadas de amostras cultivadas, localizadas no Instituto Plantarum, em Nova Odessa, São Paulo ( $47^{\circ} 19^{\prime} 51^{\prime \prime} \mathrm{W}$ e $22^{\circ} 47^{\prime} 20^{\prime}$ 'S). A temperatura média anual é de $26^{\circ} \mathrm{C}$, oscilando entre a mínima de $10^{\circ} \mathrm{C}$ e máxima de $35^{\circ} \mathrm{C}$. A umidade relativa média é de $76 \%$ e a precipitação pluviométrica é de $1.317 \mathrm{~mm} / \mathrm{ano}$. A altitude média é de $540 \mathrm{~m}$.

A prática de diafanização foi realizada no Herbário da Universidade de Brasília (UB). Para cada uma das quatro espécies, foram retiradas folhas consideradas maduras, ou seja, plenamente desenvolvidas, estando estas, em sua maioria, intactas e sem ferimentos. Foram diafanizadas 48 folhas pertencentes a Spathicarpa gardneri Schott, 54 a Spathicarpa hastifolia Hook., 48 a Spathicarpa lanceolata Engl. e 35 folhas de Spathicarpa sagittifolia Hook., totalizando 185 folhas amostradas. As folhas foram diafanizadas inteiras para que não ocorresse qualquer distorção da venação ou da forma da folha como um todo, decorrente do processo de montagem de pedaços.

A técnica de diafanização adotada (e descrita a seguir) foi a uma modificação da proposta por Shobe \& Lersten (1967), na qual, em linhas gerais, ao álcool etílico foi adicionado detergente comercial (lava-louças, princípios ativos: ácido sulfônico e lauril éter sulfato de sódio) e o cloral hidratado foi substituído por hipoclorito de sódio, além de não ser utilizado o corante fast green. Assim, a técnica utilizada no presente estudo consistiu em:

- estocar folhas frescas em álcool etílico $70 \%$ com cerca de 5-10 ml detergente comercial (lava-louças), até que os pigmentos sejam completamente ou parcialmente retirados por (período de 25 a 60 dias); - após a retirada, lavar em água destilada até a completa remoção do fixador e do detergente (3 trocas, 10 min cada);

- utilizando bandejas plásticas de $40 \times 30 \mathrm{~cm}$, colocar as folhas inteiras em solução de soda, contendo hidróxido de sódio $5 \%$ por um período de 8 a 12 horas. Alerta!: o Hidróxido de sódio $(\mathrm{NaOH})$ deve ser colocado aos poucos em água (Kraus \& Arduin, 1997);

- após este período, lavar as folhas em água destilada (novamente, 3 trocas, 10 min cada);

- colocar as folhas em bandejas plásticas contendo solução de Hipoclorito de Sódio a 5\% (água sanitária comercial; cerca de $2 \%$ de cloro ativo) por 6 a 12 horas;

lavar novamente em água destilada (3 trocas, $10 \mathrm{~min}$ cada);

- desidratar em série etanólica crescente $(10,30,50$, 70, 90 e 100\%; 1 hora cada); entre as trocas de álcool o material deve passar diretamente de solução para solução;

- passar em xileno-etanol 100\% 1:1 (2 horas);

- corar de 10-20 segundos com safranina (1\%);

- diferenciar o material por cerca de 72 horas em xileno-etanol 100\% 1:1; e finalmente;

passar em xileno (1 hora).

Cada folha diafanizada foi montada em lâminas de vidro temporárias. A montagem em duas lâminas foi utilizada para prevenir eventuais distorções dimensionais na posterior aquisição das imagens, estando as amostras, após a secagem, basicamente, planificadas. As lâminas foram secas em estufa a $45^{\circ} \mathrm{C}$ por cerca de 36 horas. Algumas lâminas permanentes foram feitas utilizando verniz acrílico da Acrilex que apresenta boa transparência, custo bastante reduzido, porém secagem lenta.

As lâminas montadas foram fotografadas digitalmente, em diferentes níveis de detalhamento (folha inteira e porções menores para evidenciar padrões acurados na venação) utilizando uma câmera SONY Cyber Shot, Modelo DSC-P200 com resolução de 7.2 MegaPixels. As fotografias foram tiradas na maior resolução, manualmente, com a câmera posicionada ortogonalmente às lâminas de vidro, deste modo, reduzindo distorções no real posicionamento das nervuras e na forma das folhas como um todo (Rohlf 2003). Algumas destas fotografias foram tratadas, digitalmente, com o auxílio do programa computacional Photoshop 6.0 (Adobe Systems 2002). 
Para a descrição e classificação dos padrões de nervação foi utilizado o Manual of Leaf Arquitecture (Leaf Architecture 1999) do Instituto Smithsonian, além de alguns padrões propostos por Hickey (1973). Finalmente, as folhas representadas na prancha são aquelas cuja forma e os padrões gerais de venação mais se repetem para cada espécie (algo como um "aspecto médio"), porém podem existir grandes variações tanto na forma quanto na arquitetura foliar (descritas anteriormente) em qualquer uma das quatro espécies.

\section{Resultados}

Descrição do padrão foliar de Spathicarpa

\section{Spathicarpa gardneri Schott}

Fig. 1, 8

Folha simples, peciolada, ovada, obovada, elíptica ou lanceolada, raramente hastada, algo assimétrica, membranácea a cartácea. Pecíolo verde claro, cilíndrico a levemente achatado, algo canaliculado, inserido marginalmente. Lâmina verde fosco adaxialmente, mais clara e brilhante abaxialmente, freqüentemente com manchas argênteas, em padrão variado; margens inteiras; base obtusa, truncada, cordada, sagitada ou hastada, por vezes assimétrica, ápice curto acuminado. Venação pinada, algo campilodriforme, camptódroma, broquidódroma, com nervuras até a quarta ordem; nervuras secundárias 5 a 7 pares, adaxialmente impressas e proeminentes abaxialmente, mais próximas entre si na porção basal, com os ângulos de divergência variando entre $25^{\circ} \mathrm{e}$ $100^{\circ}$ no último par basal; nervuras intersecundárias predominantemente exmediais, ocorrentes, sobretudo, na porção central da lâmina; nervuras terciárias sinuosas, reticuladas em polígonos regulares, ramificadas exmedialmente. Nervuras quaternárias reticuladas em polígonos regulares; aréolas bem desenvolvidas com 4 a 5 lados, em de 1 a 4 por $\mathrm{mm}^{2}$; vênulas presentes ou ausentes, quando presentes predominantemente não ramificadas, raro ramificadas uma única vez; nervura coletora (ou fimbrial), presente ou não, formada pelas terminações das veias secundárias, ao se encontrarem na margem da folha em direção ao ápice.

Ecologia: ocorre em áreas de caatinga, cerradão, florestas mesofíticas e em afloramentos calcários. É a única espécie do gênero a apresentar indivíduos de folhas variegadas.

\section{Spathicarpa hastifolia Hook.}

Fig. 2, 6

Folha simples, quase orbicular, longo-elíptica, sagitada, cordada, hastada a quase trilobada, às vezes assimétrica, membranácea. Pecíolo cilíndrico a levemente achatado, inserido marginalmente. Lâmina verde a verde escura adaxialmente, mais clara abaxialmente; margem inteira; base obtusa, truncada, cordada, hastado a hastado-tripartida; ápice obtuso a longo acuminado. Venação pinada a suprabasal actinodriforme, camptódroma, broquidódroma a eucamptódroma, com nervuras até a quarta ordem; nervuras secundárias 5 a 8 pares, impressas adaxialmente, salientes abaxialmente, mais próximas entre si na porção basal, com os ângulos de divergência variando entre $25^{\circ} \mathrm{e} 120^{\circ}$ no último par basal de algumas folhas hastado-lobadas ou hastadotripartidas; nervuras intersecundárias são predominantemente exmediais; nervuras terciárias sinuosas, reticuladas em polígonos regulares, ramificadas exmedialmente; nervuras quaternárias reticuladas em polígonos regulares; aréolas bem desenvolvidas com 4 a 5 lados, em de 1 a 5 por $\mathrm{mm}^{2}$; vênulas presentes ou ausentes, quando presentes, predominantemente não estão ramificadas, raro ramificadas uma única vez; nervura coletora (ou fimbrial), presente ou não, formada pelas terminações das veias secundárias, ao se encontrarem na margem da folha em direção ao ápice.

Ecologia: ocorre em solo bem drenado, em florestas decíduas ou semidecíduas, capões de mata e afloramentos calcários. É comum em áreas perturbadas de florestas, assim como áreas recém-abertas e roças.

\section{Spathicarpa lanceolata Engl.}

Fig. 3, 5

Folha simples, lanceolada, oblanceolada ou longoelíptica, predominantemente simétrica, membranácea a subcoriácea. Pecíolo cilíndrico, inserido marginalmente. Lâmina verde claro adaxialmente, mais clara abaxialmente; margem inteira; base aguda a obtusa; ápice acuminado. Venação pinada, camptódroma, eucamptódroma, com nervuras até quarta ordem; nervuras secundárias 7 a 9 pares, proeminentes abaxialmente, sobretudo a nervura central; espaçadas uniformemente ao longo de toda a folha, com os ângulos de divergência variando entre $25^{\circ}$ e $45^{\circ}$ no último par basal; nervuras intersecundárias predominantemente exmediais; nervuras terciárias retas a algo sinuosas, 
em polígonos regulares formando retículos alongados longitudinalmente; ramificadas exmedialmente; nervuras quaternárias reticuladas em polígonos regulares alongados; aréolas algo desenvolvidas, comumente com 4 lados, podendo apresentar 5 lados, de 2 a 4 por $\mathrm{mm}^{2}$; vênulas não observadas por dificuldades na coloração do material; nervura coletora (ou fimbrial), aparentemente, ausente.

Ecologia: ocorre em áreas de banhados nos planaltos de Santa Catarina, Rio Grande do Sul e Paraguai. É a única espécie do gênero helofitica e com distribuição subtropical.

\section{Spathicarpa sagittifolia Schott}

\section{Fig. 4, 7}

Folha simples, sagitada, cordada, algumas vezes deltóide, às vezes assimétrica, membranácea a cartácea. Pecíolo cilíndrico a levemente achatado, algo canaliculado, inserido marginalmente. Lâmina verde brilhante adaxialmente, mais clara abaxialmente; margem inteira; base truncada, cordada ou sagitada; ápice curto acuminado. Venação pinada a suprabasal actinodriforme, camptódroma, broquidódroma, com nervuras até a quarta ordem; nervuras secundárias 5 a 7 pares, levemente impressas adaxialmente, proeminentes abaxialmente, mais próximas entre si na porção basal, com os ângulos de divergência variando entre $30^{\circ} \mathrm{e} 100^{\circ}$ no último par basal de algumas folhas bastante sagitadas; nervuras intersecundárias são predominantemente exmediais, evidentes, sobretudo, na porção central da lâmina; nervuras terciárias sinuosas, reticuladas em polígonos regulares, ramificadas exmedialmente; nervuras quaternárias reticuladas em polígonos regulares; aréolas bem desenvolvidas com 4 a 5 lados, em de 1 a 5 por $\mathrm{mm}^{2}$; vênulas presentes ou ausentes, quando presentes predominantemente não ramificadas, raro ramificadas uma única vez; nervura coletora (ou fimbrial), presente ou não, formada pelas terminações das veias secundárias, ao se encontrarem na margem da folha em direção ao ápice.

Ecologia: espécie tipicamente tropical, ocorrendo em áreas da Mata Atlântica, sendo encontrada do Rio de Janeiro até a Bahia.

Chave demonstrativa da difícil circunscrição das espécies de Spathicarpa Hook. usando arquitetura foliar

1. Folha lanceolada ou estreito-elíptica; base sem lóbulos, aguda a obtusa 2

2. Venação broquidódroma; nervuras secundárias 5-8 pares, mais próximas entre si na porção basal

3. Manchas argênteas comumente presentes na lâmina foliar 1. S. gardneri

3. Manchas argênteas nunca presentes na lâmina foliar 2. S. hastifolia

2. Venação eucamptódroma; nervuras secundárias 5-9 pares, igualmente espaçadas entre si ao longo de toda a lâmina 3. S. lanceolata

1. Folha ovada, obovada, elípticas, cordadas, deltóides, trilobadas ou hastadas; base com ou sem

lóbulos, raro obtusa, geralmente cordada, sagitada, hastada ou hastado-tripartida. 4

4. Folhas hastadas a hastado-tripartidas com ângulo de divergência entre as nervuras do último par basal superior a $100^{\circ}$; lóbulos nítidos 2. S. hastifolia

4. Folhas ovadas, obovadas, elípticas, cordadas, deltóides ou hastadas, com ângulo de divergência entre as nervuras do último par basal inferiores a $100^{\circ}$; lóbulos ausentes a nítidos

\section{Discussão}

Técnica de Diafanização - Variações na técnica de diafanização de folhas proposta por Shobe \& Lersten (1967) são comuns na literatura (como em McCauley \& Evert 1988; Beebe \& Evert 1990; Dannenhoffer et al. 1990; Dannenhoffer \& Evert 1994).

A adição de detergente comercial ao álcool etílico (Gonçalves, comunicação pessoal em 2004), foi baseada na suposição que o agente que impedia a ação do fixador fosse uma resistente cutícula foliar, composta basicamente por ceras e gorduras, além de outros componentes (Esaú 1974). O longo período de imersão (25 a 60 dias) foi o suficiente para que o detergente fosse capaz de retirar esta cutícula, permitindo que o fixador penetrasse na folha e removesse grande parte de seus pigmentos.

Ressalta-se ainda que, quando as folhas foram submetidas a concentrações superiores a 5\%, tanto de $\mathrm{NaOH}$ quanto de Hipoclorito de Sódio, houve rápida 
degradação dos tecidos foliares, evidenciada pela formação de bolhas, caracterizando o descolamento da epiderme, ou completo rompimento dos tecidos, levando à destruição da amostra em questão.

Outra peculiaridade na diafanização das folhas de Spathicarpa Hook. foi a grande afinidade com o corante. Qualquer exposição da folha à safranina, superior a 20 segundos, causava coramento quase completo de todos os tecidos foliares. Se o tempo de exposição fosse curto demais, eram coradas apenas regiões circulares (em quantidades e extensão variadas) do tecido, nas quais a etapa de diferenciação agia promovendo a completa retirada do corante.

Portanto, apesar das dificuldades e das peculiaridades apresentadas pelas folhas estudadas, foi possível estabelecer um protocolo adequado de diafanização para as folhas de Spathicarpa Hook. Acredita-se ainda que esta técnica possa ser aplicada

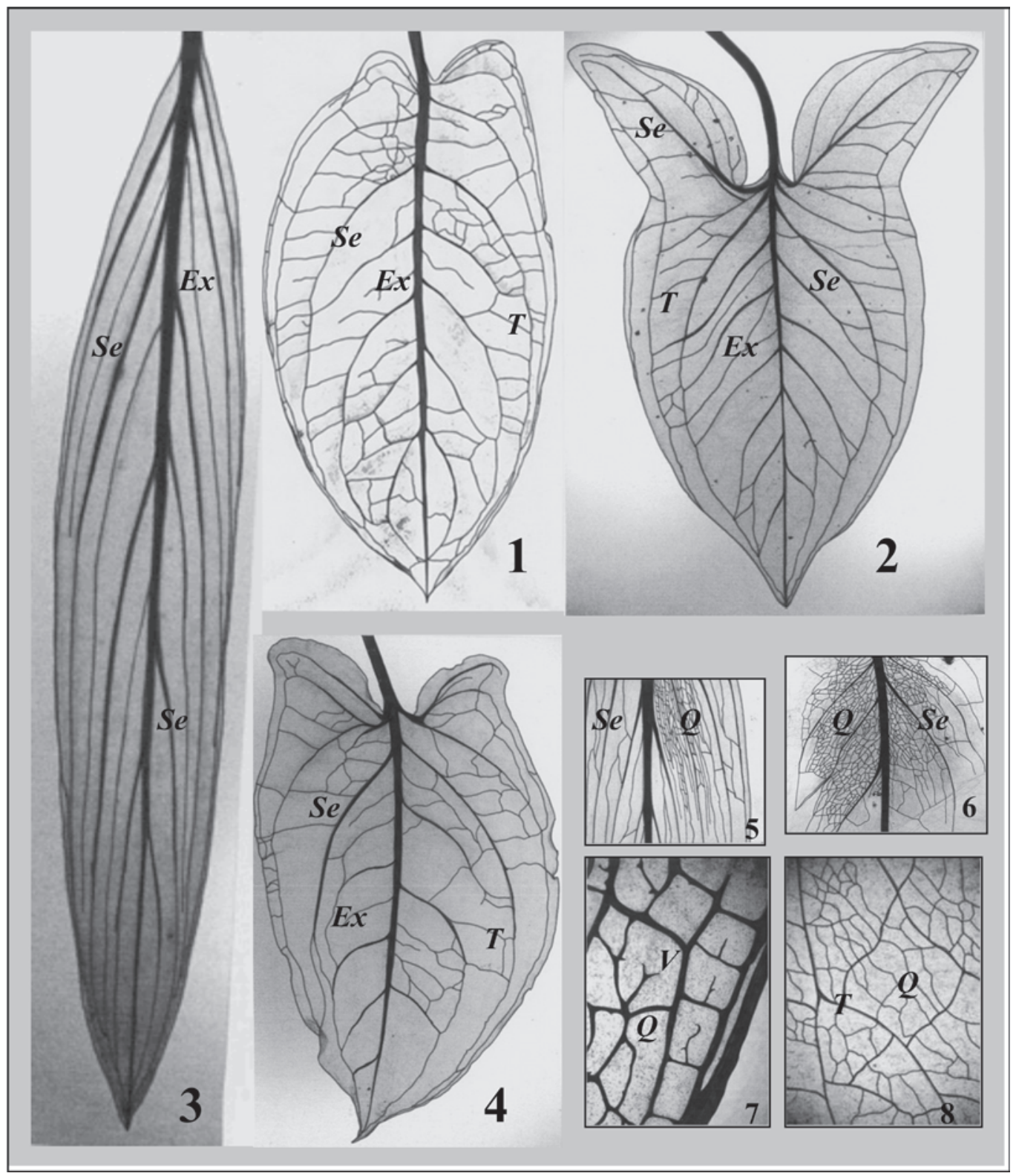

Figuras 1-8. Padrões de venação em Spathicarpa Hook. 1. Folha de Spathicarpa gardneri Schott. 2. Folha de Spathicarpa hastifolia Hook. 3. Folha de Spathicarpa lanceolata Engl. 4. Folha de Spathicarpa sagittifolia Schott. 5. Detalhe da folha de Spathicarpa lanceolata Engl. 6. Detalhe de Spathicarpa hastifolia Hook. 7. Detalhe de Spathicarpa sagittifolia Schott. 8. Detalhe de Spathicarpa gardneri Schott. (Se: nervuras secundárias; $T$ : nervuras terciárias; $Q$ : nervuras quaternárias; $E x$ : nervura exmedial; $V$ : vênulas). 
para folhas de outros gêneros de Araceae ou mesmo outras famílias de monocotiledôneas que apresentem características similares.

Arquitetura foliar de Spathicarpa - O gênero Spathicarpa Hook. apresenta um notável polimorfismo foliar. Das quatro espécies estudadas, somente Spathicarpa lanceolata Engl. apresenta características diagnósticas consistentes (folhas predominantemente lanceoladas, nunca apresentando lóbulos, base sempre aguda a obtusa; padrão geral de venação camptódromo, eucamptódromo; até 9 pares de nervuras secundárias, uniformemente dispostas ao longo da folha; ângulo de divergência do último par basal máximo de $45^{\circ}$; nervuras quaternárias reticuladas, alongadas longitudinalmente, com predominância de quatro lados).

As outras três espécies formam um complexo, compartilhando a grande maioria das características (folhas de forma variada, nunca lanceoladas, lóbulos presentes ou ausentes, padrão geral de venação camptódromo, broquidódromo a eucamptódromo; até 7(-8) pares de nervuras secundárias, mais próximas entre si na porção basal; ângulo de divergência do último par basal máximo de $120^{\circ}$; nervuras quaternárias em retículos de cinco lados). Porém, algumas tendências podem ser observadas: quanto à coloração, somente Spathicarpa gardneri Schott pode apresentar manchas argênteas na lâmina foliar, porém embora esta seja uma característica de ocorrência comum, existem folhas sem qualquer mancha e, quanto à forma, somente Spathicarpa hastifolia Hook. pode apresentar folha hastada-tripartida e Spathicarpa sagittifolia Schott, comumente sagitadas.

As folhas destas últimas três espécies de Spathicarpa Hook. exibem formas semelhantes, provavelmente, devido a questões genéticas. Tal afirmação concorda com Parkhurst \& Loucks (1972) que afirmam ser o tamanho e a forma das folhas controlados pela hereditariedade, fato demonstrado em seus estudos pela alta variação de tipos que ocorre entre diferentes espécies que coexistem num determinado ambiente.

Ainda, é conveniente lembrar que a gênese da forma foliar ocorre durante um breve período de morfogênese inicial, sendo mais influenciada pela formação das nervuras secundárias, uma vez que as nervuras de menor calibre só surgem durante a expansão da folha (Dengler \& Kang 2001). Assim, a formação e desenvolvimento das nervuras secundárias em Spathicarpa Hook. poderia ser responsável por grande parte da forma e complexidade da nervação na folha plenamente expandida, sobretudo, estando ligada ao surgimento dos lóbulos. Ressalta-se, neste ponto, que quanto maior é a complexidade do arranjo das nervuras secundárias, maior é a complexidade exibida pelos lóbulos em Spathicarpa gardneri Schott, Spathicarpa hastifolia Hook. e Spathicarpa sagittifolia Schott.

Finalmente, a espessa cutícula presente em Spathicarpa Hook. poderia atuar como elemento estabilizante da folha (Baker 1974), já que as nervuras das folhas das monocotiledôneas, comumente, não apresentam lignina associada ao xilema (Esaú 1974). A este efeito estabilizante da cutícula soma-se, provavelmente, o elevado conteúdo de água das folhas, atuando mecanicamente através do turgor, e uma estabilidade adicional na região da margem pela presença da nervura coletora.

Presença de lóbulos foliares - Folhas providas de lóbulos parecem representar um tipo foliar mais elaborado dentro de Spathicarpa Hook., podendo estar relacionadas com fatores como o desenvolvimento dos meristemas ou mesmo o diâmetro dos entrenós (Ray 1986; 1987a; 1987c). Além disso, em Spathicarpa Hook., indivíduos estiolados têm os lóbulos suprimidos ou produzem folhas relativamente mais simples, sugerindo que algum fator ambiental (Hanson 1917; Bissing 1982; Roth-Nebelsick et al. 2001), tal qual umidade, temperatura ou insolação ou, mais provavelmente, a combinação destes, também está influindo na produção dos lóbulos.

Folhas estreitas, segundo Parhurst \& Loucks (1972), parecem ser mais eficientes em condições mais secas, mais quentes e de maior insolação. Uma redução na largura da folha pode estar relacionada a um aumento na temperatura (Ezcurra et al. 1997). Ressalta-se, ainda, que um decréscimo no tamanho foliar, além de afetar propriedades mecânicas, atua também acelerando a perda de calor e reduzindo as trocas gasosas (Roth-Nebelsick et al. 2001). Assim, nas folhas de Spathicarpa lanceolata Engl. o arranjo das nervuras de forma agrupada e paralela, fisicamente, parece ser a melhor forma de estabilizar uma estrutura delgada e lanceolada, fornecendo uma adequada sustentação, necessária para manter o limbo foliar ereto em condições de campo.

Além disso, quanto maior a densidade das nervuras, mais canais por unidade de área estão disponíveis para a condução auxiliando, portanto, na transpiração e conseqüentemente na manutenção do 
suprimento de água das folhas de Spathicarpa lanceolata Engl. É conveniente lembrar que embora seu habitat característico seja os campos alagados de altitude do sul do Brasil, a água parece ser obtida às custas de elevadas taxas de transpiração, provavelmente, devido à insolação constante e a ação do vento que retirariam a umidade foliar numa taxa alta, talvez impondo a planta um déficit hídrico e nutricional em meio a tanta disponibilidade de água.

Finalmente, os resultados aqui apresentados devem ser cuidadosamente avaliados. Segundo McLellan (2000), as folhas que se desenvolveram sob condições controladas são diferentes das desenvolvidas no campo. Como os acessos estudados eram cultivados, provavelmente, as plantas de Spathicarpa Hook. receberam níveis maiores de nutrientes, tiveram uma constante disponibilidade de água e experimentaram temperaturas diferentes, quando comparadas às condições de campo. Estas diferenças podem contribuir para diferenças na arquitetura das folhas.

Estes resultados mostram ser, realmente, difícil a circunscrição das espécies Spathicarpa gardneri Schott, Spathicarpa hastifolia Hook. e Spathicarpa sagittifolia Schott, baseada em características vegetativas concordando com Gonçalves (dados não publicados). Assim, apesar de distintas do ponto de vista molecular, sua diferenciação, quanto à arquitetura foliar, não é possível. Por outro lado, Spathicarpa lanceolata Engl. constitui, claramente, uma espécie distinta das demais. Ressalta-se ainda que Milhomens (dados não publicados), utilizando a Análise Elíptica de Fourier para comparar os contornos foliares das espécies de Spathicarpa Hook., encontrou resultados similares: apenas Spathicarpa lanceolata Engl., difere das outras três espécies que têm formas foliares estatisticamente similares entre si.

Assim, das quatro espécies estudadas, somente Spathicarpa lanceolata Engl. apresenta características vegetativas diagnósticas consistentes, não sendo possível diferenciar, com base nos padrões gerais da arquitetura foliar, entre Spathicarpa hastifolia Hook., Spathicarpa gardneri Schott e Spathicarpa sagittifolia Schott.

\section{Agradecimentos}

Os autores agradecem aos professores e funcionários do Departamento de Botânica da Universidade de Brasília, IB-BOT, pelo sempre prestimoso auxílio; à Coordenação de Aperfeiçoamento de Pessoal de Nível
Superior - CAPES, pelo suporte financeiro.

\section{Referências bibliográficas}

Adobe Systens Incorporated. 2002. Photoshop 6.0. Todos os direitos reservados.

Baker, E.A. 1974. The influence of environment of leaf wax development in Brassica oleracea var. gemmifera. New Phytologist 73(5): 955-966.

Beebe, D.U. \& Evert, R.F. 1990. The morphology and anatomy of the leaf of Moricandia arvensis (L.) DC. (Brassicaceae). Botanical Gazette 151(2): 184-203.

Bissing, D.R. 1982. Evolution of leaf architecture in chaparral species Fremontodendron californicum ssp. Californicum (Sterculiaceae). American Journal of Botany 69(6): 957-972.

Croat, T.B. 1985. Collecting and preparing specimens of Araceae. Annals of the Missouri Botanical Garden 72(2): 252-258.

Dannenhoffer, J.M. \& Evert, R.F. 1994. Development of the vascular system in the leaf of barley (Hordeum vulgare L.). International Journal of Plant Science 155(2): 143-157.

Dannenhoffer, J.M.; Ebert Jr., W. \& Evert, R.F. 1990. Leaf vasculature in barley, Hordeum vulgare (Poaceae). American Journal of Botany 77(5): 636-652.

Dede, R.A. 1962. Foliar patterns in the Rutaceae. American Journal of Botany 49(5): 490-497.

Dengler, N. \& Kang, J. 2001. Vascular patterning and leaf shape. Current Opinion in Plant Biology 4: 50-56.

Dickison, W.C. 1987. Leaf and nodal anatomy and systematics of Staphyleaceae. Botanical Gazette 148(3): 475-489.

Esaú, K. 1974. Anatomia das plantas com sementes. Trad. Berta Lange de Morretes. São Paulo, Universidade de São Paulo, Edgard Blücher.

Ezcurra, C.; Ruggiero, A. \& Crisci, J.V. 1997. Phylogeny of Chuquiraga sect. Acanthophyllae (Asteraceae Barnadesioideae), and the evolution of its leaf morphology in relation to climate. Systematic Botany 22(1): 151-163.

Gonçalves, E.G. 1997. Araceae no Distrito Federal, Brasil. Dissertação de Mestrado, Universidade de Brasília, Brasília.

Gonçalves, E.G; Mayo, S.J.; Van-Sluyf, M.A. \& Salatino, A. 2007. Combined genotypic-phenotypic phylogeny of the tribe Spathicarpeae (Araceae) with reference to independent events of invasion to Andean regions. Molecular Phylogenetics and Evolution. No prelo.

Hanson, H.C. 1917. Leaf-structure as related to environment. American Journal of Botany 4(9): 533-560.

Harper, L. \& Freeling, M. 1996. Studies on early leaf development. Current Opinion in Biotechnology 7: 139-144.

Hershkovitz, M.A. 1992. Leaf morphology and taxonomic analysis of Cistanthe tweedyi (nee Lewisia tweedyi; Portulacaceae). Systematic Botany 17(2): 220-238. 
Hickey, L.J. 1973. Classification of arquitecture of dicotyledonous leaves. Botanical Gazette 60(1): 17-33.

Hickey, L.J. \& Taylor, D.W. 1991. The leaf architecture of Ticodendron and the application of foliar characters in discerning its relationships. Annals of the Missouri Botanical Garden 78: 105-130.

Kraus, J.E. \& Arduin, M. 1997. Manual básico de métodos em morfologia vegetal. Rio de Janeiro, EDUR.

Leaf Architecture Working Group. 1999. Manual of leaf Architecture - Morphological description and categorization of dicotyledonous and net-veined monocotyledonous angiosperms. Washington, DC., Department of Paleobiology, Smithsonian Institution.

McCauley, M.M. \& Evert, R.F. 1988. Morphology and vasculature of leaf of potato (Solanum tuberosum). American Journal of Botany 75(3): 377-390.

McLellan, T. 2000. Geographic variation and plasticity of leaf shape and size in Begonia dregei and B. homonyma (Begoniaceae). Botanical Journal of Linnean Society 132: 79-95.

Murata, J. 1990. Diversity of shoot morphology in Typhonium (Araceae). American Journal of Botany 77(11): 1475-1481.

Parkhurst, D.F. \& Loucks, O.L. 1972. Optimal leaf size in relation to environment. Journal of Ecology 60(2): 505-537.
Ray, T.S. 1986. Growth correlations within the segment in the Araceae. American Journal of Botany 73: 993-1001.

Ray, T.S. 1987a. Leaf types in the Araceae. American Journal of Botany 74(9): 1359-1372.

Ray, T.S. 1987b. Diversity of shoot organization in the Araceae. American Journal of Botany 74(9): 1373-1387.

Ray, T.S. 1987c. Cyclic heterophylly in Singonium (Araceae). American Journal of Botany 74(1): 16-26.

Ray, T.S. 1988. Survey of shoot organization in the Araceae. American Journal of Botany 75(1): 56-84.

Ray, T.S. 1990. Metamorphosis in the Araceae. American Journal of Botany 77(12): 1599-1609.

Rohlf, F.J. 2003. Bias and error in estimates of mean shape in geometric morphometrics. Journal of Human Evolution 44: 665-683.

Roth-Nebelsick, A.; Uhl, D.; Mosbrugger, V. \& Kerp, H. 2001. Evolution and function of leaf venation architecture: a review. Annals of Botany 87: 553-566.

Sinha, N. 1999. Leaf development in angiosperms. Annual Review of Plant Physiology and Plant Molecular Biology 50: 419-446.

Shobe, W.R. \& Lersten, N.R. 1967. A technique for clearing and staining Gymnosperm leaves. Botanical Gazette 128(2): 150-152.

Stace, C.A. 1989. Plant taxonomy and biosystematics. $2^{\text {nd }}$ ed., Cambridge, Cambridge University Press. 